\title{
Influences of temperature, power ultrasound and reaction time on the morphological properties of two new mercury(II) coordination supramolecular compounds
}

\author{
Payam Hayati ${ }^{a}$, Ali Reza Rezvani ${ }^{\text {a,* }}$, Ali Morsali ${ }^{\text {b,* }}$, Pascal Retailleau ${ }^{c}$, S. García-Granda ${ }^{\text {d }}$ \\ ${ }^{a}$ Department of Chemistry, Faculty of Science, University of Sistan and Baluchestan, Zahedan P.O. Box 98135-674, Iran \\ ${ }^{b}$ Department of Chemistry, Faculty of Sciences, Tarbiat Modares University, P.O. Box 14115-4838, Tehran, Islamic Republic of Iran \\ ' Institut de Chimie des Substances Naturelles, CNRS UPR 2301, Univ. Paris-Sud, Université Paris-Saclay, 1, av. de la Terrasse, 91198 Gif-sur-Yvette, France

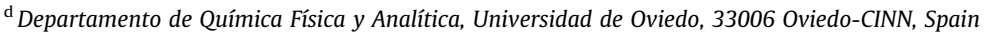

\section{A R T I C L E I N F O}

\section{Article history:}

Received 29 June 2016

Received in revised form 24 July 2016

Accepted 25 July 2016

Available online 26 July 2016

\section{Keywords:}

Coordination supramolecular

Sonochemical process

Ultrasound irradiation

Morphology

Topology

\begin{abstract}
A B S T R A C T
Nanoparticles of two new coordination compounds, $\left[\mathrm{Hg}_{2}(\mathrm{~L})_{2}(\mathrm{Br})_{4}\right]_{n}(\mathbf{1})$ and $\left[\mathrm{Hg}\left(\mathrm{L}^{\prime}\right)(\mathrm{SCN})_{2}\right](\mathbf{2})$, ( $\mathrm{L}=2$-amino-4-methylpyridine, $\mathrm{L}^{\prime}=2,6$-pyridinedicarboxlic acid), have been synthesized by use of a sonochemical process and characterized by scanning electron microscopy (SEM), field emission scanning electron microscopy(FESEM), X-ray powder diffraction (XRPD), Fourier transform infrared spectroscopy (FTIR) spectroscopy and elemental analyses. The single crystal X-ray data of compounds $\mathbf{1}$ and $\mathbf{2}$ imply that the $\mathrm{Hg}(\mathrm{II})$ ions are four and five coordinated, respectively. Topological analysis shows that $1 \mathrm{D}$ and OD coordination networks of $\mathbf{1}$ and $\mathbf{2}$ can be classified as underlying nets of topological types $2 \mathrm{C} 1$ and 1,3M4-1, respectively. The thermal stability of compounds has been studied by thermal gravimetric (TG) and differential thermal analyses (DTA). The role of temperature, reaction time and ultrasound irradiation power on the size and morphology of "nano-structures" $\mathbf{1}$ and $\mathbf{2}$, has been investigated. Results claim that an increase of temperature, sonication power and decrease in reaction time leads to a decrease of particle size.
\end{abstract}

(c) 2016 Elsevier B.V. All rights reserved.

\section{Introduction}

Over the last two decades, the rational design and syntheses of novel coordination supramolecular compounds are making considerable progress in the field of supramolecular chemistry and crystal engineering [1-5]. Chemists and materials scientists studied metal coordination supramolecular compounds widely, as they quite simply exhibit numerous potentially useful applications in molecular adsorption, catalysis, magnetism, luminescence, nonlinear optics, and molecular sensing which are not found in mononuclear compounds [6-11]. Mercury(II) is really a well-known metal with a variety of applications in numerous areas. However, mercury has been used for the fabrication of coordination polymers and supramolecule [12-18]. The $\mathrm{d}^{10}$ configuration in the $\mathrm{Hg}(\mathrm{II})$ ion is assigned to a flexible coordination environment to ensure that different geometries can be generated to tailor-made materials. The coordination polymers in this metal ion can be synthesized [13]. For almost all chemists the power of ultrasound stems from the belief that it includes a kind of energy for the modification of

\footnotetext{
* Corresponding authors.

E-mail address: morsali_a@modares.ac.ir (A. Morsali).
}

chemical reactivity, which is different from that normally, used e.g. heat, light and pressure. Power ultrasound produces its effect via cavitation bubbles. These bubbles are generated over the cycle in the wave in the event the liquid structure is torn apart to create tiny voids, which collapse in the compression cycle. It has been calculated that pressures within bubbles can rise to many hundreds of atmospheres and temperature can reach several thousand degrees are degrees on the collapse of those bubbles [19]. These extreme conditions can drive chemical reactions, which have been designed to fabricate several different nano compounds [20]. In the past few years, many different types of nanomaterials have been made by this method [21-31].

Synthesis and characterization of coordination polymers with various particle sizes and morphologies are crucial to the basics of technological applications. In nano sizes' particles, the ratio of surface area to volume is vastly increased when compared to compounds with larger particle. The size effect actually starts to play a substantial role on chemical and physical properties such as catalytic activity change when compared to bulk systems [32]. The results of ultrasound radiation on chemical reactions were reported in the recent works [33-42]. In this paper, we certainly have designed a simple sonochemical process to make 
Table 1

Crystal data and structures refinement for $\left[\mathrm{Hg}_{2}(\mathrm{~L})_{2}(\mathrm{Br})_{4}\right]_{\mathrm{n}}(\mathbf{1})$ and $\left[\mathrm{Hg}\left(\mathrm{L}^{\prime}\right)(\mathrm{SCN})_{2}\right](\mathbf{2})$.

\begin{tabular}{|c|c|c|}
\hline Empirical formula & $\mathrm{C}_{12} \mathrm{H}_{16} \mathrm{Br}_{4} \mathrm{Hg}_{2} \mathrm{~N}_{4}$ & $\mathrm{C}_{9} \mathrm{H}_{5} \mathrm{HgN}_{3} \mathrm{O}_{4} \mathrm{~S}_{2}$ \\
\hline Formula weight & 937.11 & 483.87 \\
\hline Temperature & $293(2) \mathrm{K}$ & $293(2) \mathrm{K}$ \\
\hline Wavelength & $0.71075 \AA$ & $0.71075 \AA$ \\
\hline Crystal system & Monoclinic & Triclinic \\
\hline Space group & $\mathrm{P} 2_{1} / \mathrm{n}$ & $\mathrm{P}_{1}$ \\
\hline Unit cell dimensions & $\begin{array}{l}\mathrm{a}=7.6884(6) \AA, \alpha=90^{\circ} \\
\mathrm{b}=21.4711(16) \AA, \beta=95.587(7)^{\circ} \\
\mathrm{c}=12.7021(9) \AA, \gamma=90^{\circ}\end{array}$ & $\begin{array}{l}\mathrm{a}=8.0798(7) \AA, \alpha=100.489(11)^{\circ} \\
\mathrm{b}=8.4352(7) \AA, \beta=92.030(12)^{\circ} \\
\mathrm{c}=10.5239(9) \AA, \gamma=115.287(10)^{\circ}\end{array}$ \\
\hline Volume & $2086.9(3) \AA^{3}$ & $632.50(11) \AA^{3}$ \\
\hline Z & 4 & 2 \\
\hline Density(calculated) & $2.98247 \mathrm{~g} / \mathrm{cm}^{3}$ & $2.54051 \mathrm{~g} / \mathrm{cm}^{3}$ \\
\hline Absorption coefficient & $22.354 \mathrm{Mg} / \mathrm{m}^{3}$ & $22.354 \mathrm{Mg} / \mathrm{m}^{3}$ \\
\hline $\mathrm{F}\left(\begin{array}{llll}0 & 0 & 0\end{array}\right)$ & 1664.0 & 448.0 \\
\hline Crystal size & $0.37 \times 0.13 \times 0.1 \mathrm{~mm}^{3}$ & $0.40 \times 0.25 \times 0.20 \mathrm{~mm}^{3}$ \\
\hline Theta range for data collection & $3.380-27.488^{\circ}$ & $3.716-27.575^{\circ}$ \\
\hline Reflections collected & 19,816 & 11,708 \\
\hline$\mu$ & $22.35 \mathrm{~mm}^{-1}$ & $12.51 \mathrm{~mm}^{-1}$ \\
\hline \multirow[t]{3}{*}{ Index ranges } & $-9 \leqslant h \leqslant 9$ & $-10 \leqslant h \leqslant 10$ \\
\hline & $-23 \leqslant k \leqslant 27$ & $-10 \leqslant k \leqslant 10$ \\
\hline & $-15 \leqslant 1 \leqslant 16$ & $-13 \leqslant 1 \leqslant 13$ \\
\hline$h, k, l(\max )$ & $9,27,16$ & $10,10,13$ \\
\hline$(\sin \theta / \lambda) \max$ & $0.649 \AA^{-1}$ & $0.651 \AA^{-1}$ \\
\hline Theta (max) & $27.488^{\circ}$ & $27.575^{\circ}$ \\
\hline Radiation type & Mo K $\alpha$ & Mo K $\alpha$ \\
\hline Refinement method & Full-matrix least-squares on $\mathrm{F}^{2}$ & Full-matrix least-squares on $\mathrm{F}^{2}$ \\
\hline Data/restraints/parameters & $4746 / 0 / 204$ & $2902 / 2 / 176$ \\
\hline Goodness-of-fit-on $\mathrm{F}^{2}$ & 0.974 & 0.984 \\
\hline \multirow[t]{3}{*}{ Refinement } & $\mathrm{R}\left[\mathrm{F}^{2}>2 \sigma\left(\mathrm{F}^{2}\right)\right]=0.061$ & $\mathrm{R}\left[\mathrm{F}^{2}>2 \sigma\left(\mathrm{F}^{2}\right)\right]=0.037$ \\
\hline & $w R\left(F^{2}\right)=0.158$ & $\mathrm{wR}\left(\mathrm{F}^{2}\right)=0.087$ \\
\hline & $S=0.97$ & $S=0.95$ \\
\hline $\mathrm{R} 1[\mathrm{I}>2 \sigma(\mathrm{I})]$ & $20,154,4746,2375$ & $11,717,2902,2507$ \\
\hline Rint & 0.136 & 0.065 \\
\hline Extinction coefficient & $0.00081(9)$ & $\mathrm{n} / \mathrm{a}$ \\
\hline Largest diff. peak and hole & 1.710 and $-1.341 \mathrm{eA}^{-3}$ & $3.03,-2.35$ e $\AA^{-3}$ \\
\hline CCDC No. & $1,442,314$ & $1,442,310$ \\
\hline
\end{tabular}

nano-structures of $\left[\mathrm{Hg}_{2}(\mathrm{~L})_{2}(\mathrm{Br})_{4}\right]_{\mathrm{n}}$ and $\left[\mathrm{Hg}\left(\mathrm{L}^{\prime}\right)(\mathrm{SCN})_{2}\right]$, The ultrasonic power, sonicating time, the temperature of reaction were the parameters that have been changed for reaching the optimized condition. Among the potential characterization methods such as scanning electron microscopy (SEM), field emission scanning electron microscope (FESEM) and powder X-ray diffraction (PXRD) were used.

\section{Experimental}

\subsection{Materials and physical techniques}

Starting reagents for the synthesis were purchased and used without any purification from industrial suppliers (Sigma-Aldrich, Merck and others). Elemental analyses (carbon, hydrogen, and nitrogen) were performed employing a Heraeus Analytical Jena, Multi EA 3100 CHNO rapid analyzer. Fourier transform infrared spectra were recorded on a FT-IR JASCO 680-PLUS spectrometer as $\mathrm{KBr}$ pellets in the $4000-400 \mathrm{~cm}^{-1}$ spectral range. Thermogravimetric analysis (TGA) and differential thermal analyses (DTA) of

Table 2

Selected bond lengths $/ \mathrm{A}^{\circ}$ for compound $\left[\mathrm{Hg}_{2}(\mathrm{~L})_{2}(\mathrm{Br})_{4}\right]_{\mathrm{n}}$.

\begin{tabular}{llll}
$\mathrm{Hg}(1)-\mathrm{Br}(1)$ & $2.9542(15)$ & $\mathrm{N}(4)-\mathrm{H}(4) \mathrm{A}$ & 0.8623 \\
$\mathrm{Hg}(1)-\mathrm{N}(1)$ & $2.233(10)$ & $\mathrm{N}(4)-\mathrm{H}(4) \mathrm{B}$ & 0.8495 \\
$\mathrm{Hg}(1)-\mathrm{Br}(3)$ & $2.4954(15)$ & $\mathrm{O}(1) \mathrm{W}-\mathrm{H}(1) \mathrm{WB}$ & 0.8500 \\
$\mathrm{Hg}(1)-\mathrm{Br}(2)$ & $2.5642(16)$ & $\mathrm{C}(9)-\mathrm{H}(9) \mathrm{A}$ & 0.9600 \\
$\mathrm{Br}(1)-\mathrm{Hg}(2)$ & $2.5622(15)$ & $\mathrm{C}(13)-\mathrm{H}(13) \mathrm{A}$ & 0.9600 \\
$\mathrm{Hg}(2)-\mathrm{Br}(2)^{\mathrm{i}}$ & $2.9737(15)$ & $\mathrm{Br}(2)-\mathrm{Hg}(2)^{\mathrm{ii}}$ & $2.9737(15)$ \\
$\mathrm{C}(1)-\mathrm{N}(1)$ & $1.370(17)$ & $\mathrm{N}(2)-\mathrm{H}(2) \mathrm{A}$ & 0.8706 \\
$\mathrm{C}(1)-\mathrm{C}(2)$ & $1.35(2)$ & $\mathrm{N}(2)-\mathrm{H}(2) \mathrm{B}$ & 0.8720 \\
\hline
\end{tabular}

Symmetry transformations used to generate equivalent atoms:

i $1+x, y, z$;

ii $-1+x, y, z$. the title compound were performed on a computer-controlled STA-PT 1500 apparatus. single-phased powder sample of 1-1, 21 and crystal structure of compounds 1,2 were loaded into alumina pans and heated with a ramp rate of $10{ }^{\circ} \mathrm{C} / \mathrm{min}$ from room temperature to $600{ }^{\circ} \mathrm{C}$ under argon atmosphere. X-ray diffraction experiments were carried out at the $\mathrm{MoK} \alpha$ wavelength at ambient temperature. A microfocused Rigaku mm003 source with

Table 3

Selected bond lengths $/ \mathrm{A}^{\circ}$ for compound $\left[\mathrm{Hg}\left(\mathrm{L}^{\prime}\right)(\mathrm{SCN})_{2}\right]$.

\begin{tabular}{llll}
\hline $\mathrm{Hg}(1)-\mathrm{N}(1)$ & $2.504(5)$ & $\mathrm{C}(5)-\mathrm{C}(7)$ & $1.507(8)$ \\
$\mathrm{Hg}(1)-\mathrm{S}(1)$ & $2.379(2)$ & $\mathrm{N}(2)-\mathrm{C}(9)$ & $1.149(9)$ \\
$\mathrm{Hg}(1)-\mathrm{O}(1)$ & $2.641(4)$ & $\mathrm{S}(2)-\mathrm{C}(9)$ & $1.674(7)$ \\
$\mathrm{Hg}(1)-\mathrm{S}(2)$ & $2.394(2)$ & $\mathrm{C}(3)-\mathrm{H}(3)$ & 0.9300 \\
$\mathrm{C}(1)-\mathrm{N}(1)$ & $1.337(8)$ & $\mathrm{C}(6)-\mathrm{O}(4)$ & $1.307(8)$ \\
$\mathrm{O}(4)-\mathrm{H}(4) \mathrm{A}$ & 0.8200 & $\mathrm{O}(2)-\mathrm{C}(7)$ & $1.311(8)$ \\
$\mathrm{O}(4)-\mathrm{H}(4) \mathrm{A}$ & 0.8200 & $\mathrm{O}(3)-\mathrm{C}(6)$ & $1.217(9)$ \\
$\mathrm{N}(3)-\mathrm{C}(8)$ & $1.148(10)$ & $\mathrm{C}(2)-\mathrm{H}(2)$ & 0.9300 \\
\hline
\end{tabular}

Table 4

Selected bond lengths $/ \mathrm{A}^{\circ}$ for compound $\left[\mathrm{Hg}_{2}(\mathrm{~L})_{2}(\mathrm{Br})_{4}\right]_{\mathrm{n}}$.

\begin{tabular}{llll} 
N1-Hg1-Br1 & $91.3(3)$ & N3-Hg2-Br1 & $107.3(3)$ \\
N1-Hg1-Br3 & $126.4(3)$ & N3-Hg2-Br2 & $88.3(3)$ \\
N1-Hg1-Br2 & $106.7(3)$ & N3-Hg2-Br4 & $125.5(3)$ \\
Br3-Hg1-Br1 & $96.01(5)$ & Br4-Hg2-Br1 & $126.27(6)$ \\
Br3-Hg1-Br2 & $125.87(6)$ & Br4-Hg2-Br2 & $97.63(5)$ \\
Br2-Hg1-Br1 & $92.24(5)$ & Hg1-Br2-Hg2 & $90.54(4)$ \\
Hg2-Br1-Hg1 & $92.16(4)$ & C6-N1-C1 & $118.0(12)$ \\
Br1-Hg2-Br2 & $93.12(5)$ & C6-N1-Hg1 & $123.3(9)$ \\
\hline
\end{tabular}

Symmetry transformations used to generate equivalent atoms:

i $1+x, y, z$;

ii $-1+x, y, z$ 
integrated confocal caxFlux double bounce optic was employed, and Bragg peak measurement was performed by an HPAD Pilatus $200 \mathrm{~K}$ detector. The structure was solved using direct methods, refined on $\mathrm{F}^{2}$ by means of full-matrix least-squares methods [35] and expanded using Fourier techniques. All non-hydrogen atoms were refined anisotropically. Hydrogen atoms were included in structure factor calculations from their location in difference maps. $\mathrm{C}$-bound $\mathrm{H}$ atoms were treated as riding in geometrically idealized positions, with Uiso $(\mathrm{H})=\mathrm{kUeq}(\mathrm{C})$, where $\mathrm{k}=1.2$ for the $\mathrm{Csp}^{2}$ bound $\mathrm{H}$ atoms. For the water molecules, the oxygen-hydrogen bond lengths were restrained to $0.82(2) \AA$ (DFIX instruction) and the hydrogen-hydrogen intramolecular distances were restrained to $1.30(4) \AA$ (DANG instruction). The Uiso value for hydrogen atoms were set to 1.5 times the value of the water oxygen atom. Computing details [34-36]: data collection, cell refinement and data reduction: CrystalClear-SM expert 2.1b43 (Rigaku, 2014); program(s) used to solve structure: SHELXT [35]; $\operatorname{program}(\mathrm{s})$ used to refine structure: SHELXL-2014/7 [35]; molecular graphics: PLATON [36]; software used to prepare material for publication. A multi wave ultrasonic generator (ultrasonic homogenizer-UP 400-A, IRAN), equipped with a converter/transducer and titanium oscillator (horn), $12.5 \mathrm{~mm}$ in diameter, operating at $20 \mathrm{kHz}$ with a maximum power output of $400 \mathrm{~W}$, were used for the ultrasonic irradiation. Melting points were measured on an electrothermal 9100 apparatus and are uncorrected. X-ray powder diffraction (XRD) measurements were performed using an X'pert diffractometer manufactured by Philips with monochromatized Cuk $\alpha$ radiation and simulated XRD powder patterns based on single crystal data were prepared using the Mercury software [37]. The samples were characterized with a scanning electron microscope (SEM) (Philips XL 30 and S-4160) and field emission scanning electron microscope (FE-SEM) (Perkin Elmer Elan 9000) with gold coating.

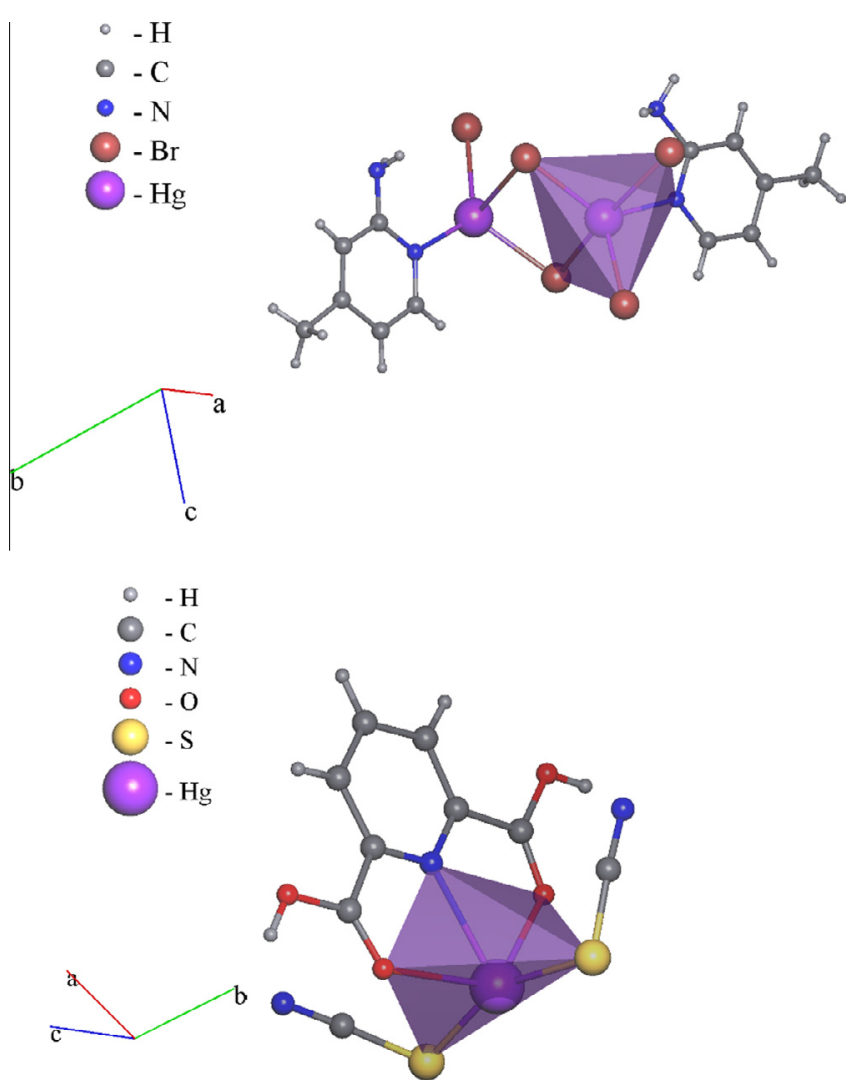

Fig. 1. The coordination environment of $\mathrm{Hg}^{+2}$ cation environment in compound $\left[\mathrm{Hg}_{2}(\mathrm{~L})_{2}(\mathrm{Br})_{4}\right]_{\mathrm{n}}$ (up) and in compound $\left[\mathrm{Hg}\left(\mathrm{L}^{\prime}\right)(\mathrm{SCN})_{2}\right]$ (down).

\subsection{Synthesis of $\left[\mathrm{Hg}_{2}(\mathrm{~L})_{2}(\mathrm{Br})_{4}\right]_{n}(\mathbf{1})$ as single crystal}

$\mathrm{HgCl}_{2}$ (1 mmol, $0.271 \mathrm{~g}$ ), 2-Amino-4-methylpyridine (1 mmol, $0.108 \mathrm{~g}$ ) and potassium bromide $(2 \mathrm{mmol}, 0.238 \mathrm{~g}$ ) were loaded into one arm of a branch tube and both of the arms were filled slowly by water. The chemical bearing arm was immersed in an oil bath kept at $60^{\circ} \mathrm{C}$. Crystals were formed on the inside surface of the arm kept at ambient temperature, After 10 days, colorless crystals were deposited in the cooler arm were filtered off, washed with water and air dried. (0.286 g, yield $61.12 \%$ based on final product), m.p. $=150{ }^{\circ} \mathrm{C}$. Anal. Calc. for $\mathrm{C}_{12} \mathrm{H}_{16} \mathrm{Br}_{4} \mathrm{Hg}_{2} \mathrm{~N}_{4}$ : C: $15.36, \mathrm{H}$ : 1.70, N: 11.95\%; Found C: $15.24 \mathrm{H}: 1.33 \mathrm{~N}: 11.78 \%$. IR (selected bands for compound 1; in $\mathrm{cm}^{-1}$ ): 3454.30 (s), 3359.69 (s), 3035.49 (w), 1631.77 (vs), 1454.53 (s) $\mathrm{cm}^{-1}$.

\subsection{Synthesis of $\left[\mathrm{Hg}_{2}(\mathrm{~L})_{2}(\mathrm{Br})_{4}\right]_{n}$ (1) nano-structures under ultrasonic irradiation}

To prepare the nano-structures of $\left[\mathrm{Hg}_{2}(\mathrm{~L})_{2}(\mathrm{Br})_{4}\right]_{\mathrm{n}}$ (1) by sonochemical process, a high-density ultrasonic probe immersed directly into the solution of $\mathrm{HgCl}_{2}(20 \mathrm{ml}, 0.05 \mathrm{M})$ in water, then into this solution, a proper volume of 2-amino-4-methylpyridine ligand and $\mathrm{KBr}$ in water solvent $(20 \mathrm{ml}, 0.05 \mathrm{M})$ was added in a drop wise manner. The solution was irradiated by sonochemical with the power of $60 \mathrm{~W}$ and temperature $50{ }^{\circ} \mathrm{C}$ for $1 \mathrm{~h}$. For the study of the effect of time of reaction on size and morphology of nano- structured compound $\mathbf{1}$, the above processes were done with $30 \mathrm{~min}$ and for the study of the effect of sonication power with
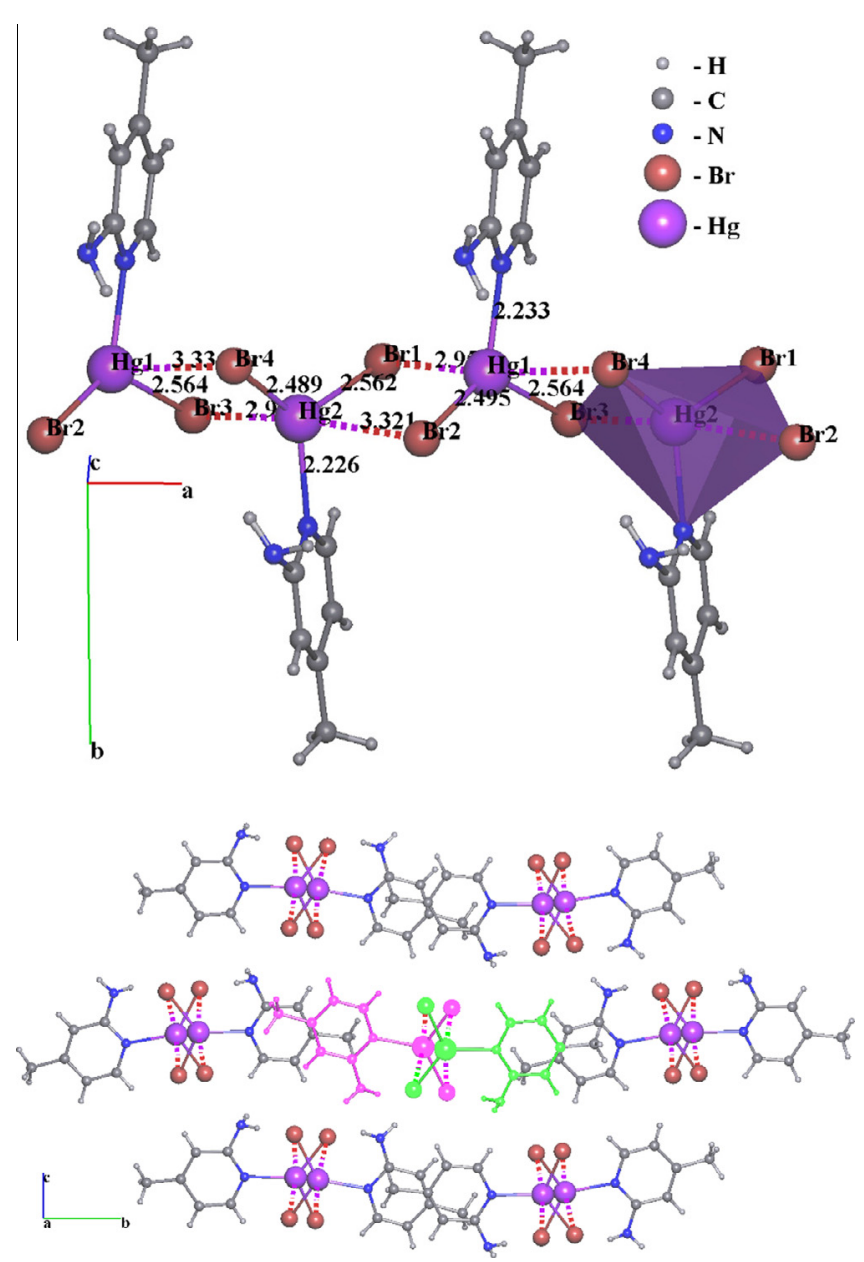

Fig. 2. Six chains surrounding the central one. Dashed lines represent van-derwaales bonded (down). Distance of bounds in 1 (up). 
$80 \mathrm{~W}$ (time: $1 \mathrm{~h}$, temperature: $50^{\circ} \mathrm{C}$, concentration: $0.05 \mathrm{M}$ ) also for the study of the effect of temperature with $80^{\circ} \mathrm{C}$ (time: $1 \mathrm{~h}$, sonication power: $60 \mathrm{~W}$, concentration: $0.05 \mathrm{M}$ ) has been done too. The obtained precipitates were filtered, subsequently washed with water and then dried. $(0.312 \mathrm{~g}$, yield $64.19 \%$ based on final product), m.p. $=166{ }^{\circ} \mathrm{C}$. Anal. Calc. for $\mathrm{C}_{12} \mathrm{H}_{16} \mathrm{Br}_{4} \mathrm{Hg}_{2} \mathrm{~N}_{4}$ : C: 15.36, H: 1.70, N: $11.95 \%$; Found C: $15.28 \mathrm{H}: 1.62 \mathrm{~N}: 11.82 \%$. IR (selected bands for compound 1; in $\mathrm{cm}^{-1}$ ): 3455.48 (s), 3360.25 (s), 3035.55 (w), 1632.14 (vs), 1454.81 (s) $\mathrm{cm}^{-1}$.

\subsection{Synthesis of $\left[\mathrm{Hg}\left(L^{\prime}\right)(\mathrm{SCN})_{2}\right]$ (2) as single crystal}

$\mathrm{HgCl}_{2}$ (1 mmol, $0.271 \mathrm{~g}$ ), 2, 6-pyridinedicarboxlic acid (1 mmol, $0.167 \mathrm{~g}$ ) and $\mathrm{KSCN}$ ( $2 \mathrm{mmol}, 0.18 \mathrm{~g}$ ) were loaded into one arm of a branch tube and both of the arms were filled slowly by water. The chemical bearing arm was immersed in an oil bath kept at $60^{\circ} \mathrm{C}$. Crystals were formed on the inside surface of the arm kept at ambient temperature, after10 days, colorless crystals were deposited in the cooler arm were filtered off, washed with water and air dried. ( $0.343 \mathrm{~g}$, yield $71.01 \%$ based on final product), m.p. $=180{ }^{\circ} \mathrm{C}$. Anal. Calc. for $\mathrm{C}_{9} \mathrm{H}_{5} \mathrm{Hg} \mathrm{N}_{3} \mathrm{O}_{4} \mathrm{~S}_{2}$ : C: $22.32, \mathrm{H}: 1.03$, N: 17.36\%; Found C: $22.21 \mathrm{H}: 0.98 \mathrm{~N}: 17.30 \%$. IR (selected bands for compound 2; in $\mathrm{cm}^{-1}$ ): 3442.27 (br), 3092.48 (w), 2109.16 (vs), 2141.45 (w), 1716.94 (vs).

\subsection{Synthesis of $\left[\mathrm{Hg}\left(\mathrm{L}^{\prime}\right)(\mathrm{SCN})_{2}\right]$ (2) nano-structures under ultrasonic irradiation}

To prepare the nano-structures of $\left[\mathrm{Hg}\left(\mathrm{L}^{\prime}\right)(\mathrm{SCN})_{2}\right](2)$ by another sonochemical process, a high-density ultrasonic probe immersed directly into the solution of $\mathrm{HgCl}_{2}(20 \mathrm{ml}, 0.05 \mathrm{M})$ in water, then into this solution, a proper volume of 2, 6-pyridinedicarboxlic acid ligand and $\mathrm{KSCN}$ in water solvent $(20 \mathrm{ml}, 0.05 \mathrm{M})$ was added in a drop wise manner. The solution was irradiated by sonochemical with the power of $60 \mathrm{~W}$ and temperature $50{ }^{\circ} \mathrm{C}$ for $1 \mathrm{~h}$. For the study of the effect of time of reaction on size and morphology of nano- structured compound $\mathbf{2}$, the above processes were done with $30 \mathrm{~min}$ and for the study of the effect of sonication power with $80 \mathrm{~W}$ (time: $1 \mathrm{~h}$, temperature: $50^{\circ} \mathrm{C}$, concentration: $0.05 \mathrm{M}$ ) also for the study of the effect of temperature with $80^{\circ} \mathrm{C}$ (time: $1 \mathrm{~h}$, sonication power: $60 \mathrm{~W}$, concentration: $0.05 \mathrm{M}$ ) has been done too. The obtained precipitates were filtered, subsequently washed with water and then dried. $(0.356 \mathrm{~g}$, yield $73.70 \%$ based on final product), m.p $\sim 199{ }^{\circ} \mathrm{C}$. Anal. Calc. for $\mathrm{C}_{9} \mathrm{H}_{5} \mathrm{HgN}_{3} \mathrm{O}_{4} \mathrm{~S}_{2}$ : C: 22.32 , $\mathrm{H}: 1.03$, N: 17.36\%; Found C: $22.27 \mathrm{H}: 1.02 \mathrm{~N}: 17.35 \%$. IR (selected bands for compound 2; in $\mathrm{cm}^{-1}$ ): 3441.55 (br), 3096.38 (w), 2108.75 (vs), 2140.93 (w), 1716.90 (vs).

\section{Results and discussion}

Reaction between the organic nitrogen-donor 2-amino-4methylpyridine ligand (L), potassium bromide, and mercury(II) chloride yielded crystalline material formulated as new $1 \mathrm{D}$ coordination polymer $\left[\mathrm{Hg}_{2}(\mathrm{~L})_{2}(\mathrm{Br})_{4}\right]_{\mathrm{n}}(\mathbf{1})$. Utilizing 2,6-pyridinedicarboxlic acid for $\mathrm{N}, \mathrm{O}$-donor ligand in mixture of $\mathrm{KSCN}$ and $\mathrm{HgCl}_{2}$ leads to formation of new molecular coordination compound $\left[\mathrm{Hg}\left(\mathrm{L}^{\prime}\right)(\mathrm{SCN})_{2}\right]$ (2). Nanocrystals of compound $\mathbf{1}$ and $\mathbf{2}$ were obtained in aqueous solution by ultrasonic irradiation. Single crystals of compound 1 and 2, suitable for X-ray crystallography, were prepared by thermal gradient method applied to an aqueous solution of

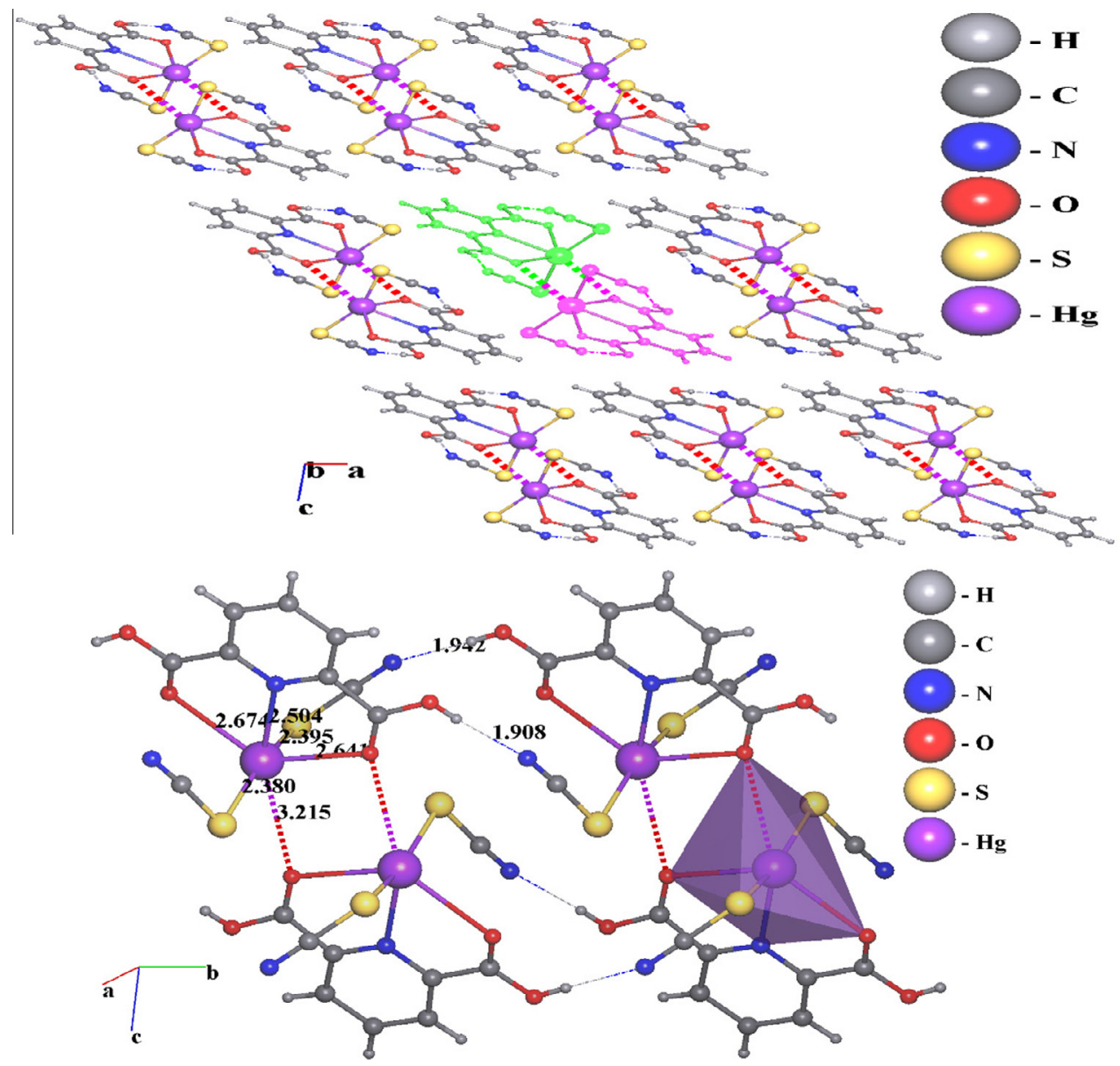

Fig. 3. Eight chains surrounding the central one. Dashed lines represent H-bonds (up). Distance of bounds in 2 (down). 

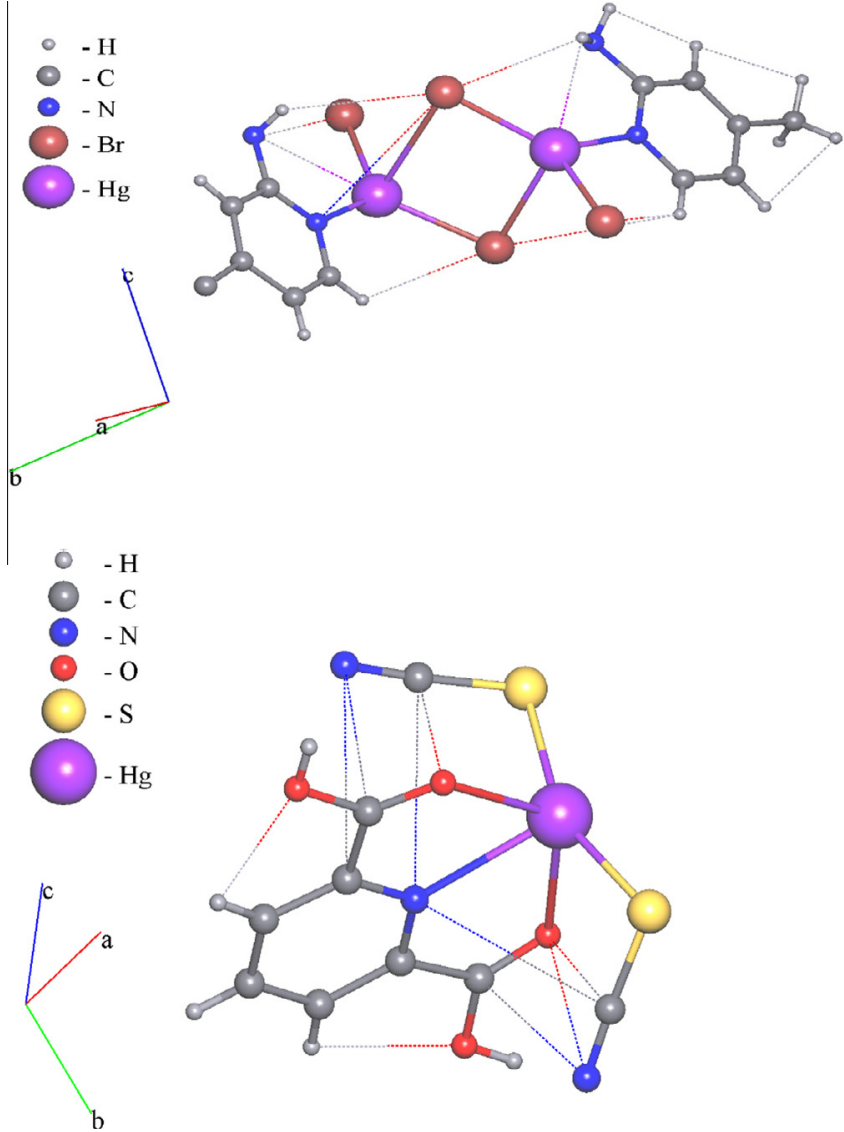

Fig. 4. Weak interaction in asymmetric units (up) compound 1, (down) compound 2. the reagents the "branched tube method". $\left[\mathrm{Hg}_{2}(\mathrm{~L})_{2}(\mathrm{Br})_{4}\right]_{\mathrm{n}}$ and $\left[\mathrm{Hg}\left(\mathrm{L}^{\prime}\right)(\mathrm{SCN})_{2}\right]$ synthesized by using the two different routes (branched tube and ultrasonic method). Single crystal X-ray diffraction analysis (Tables 1-4) of compounds $\mathbf{1}$ and $\mathbf{2}$ was carried out and the coordination environment of the title complexes are shown in (Fig. 1) Single X-ray crystal analysis reveals that $\left[\mathrm{Hg}_{2}(\mathrm{~L})_{2}(\mathrm{Br})_{4}\right]_{\mathrm{n}}(\mathbf{1})$ and $\left[\mathrm{Hg}\left(\mathrm{L}^{\prime}\right)(\mathrm{SCN})_{2}\right](\mathbf{2})$ complexes crystallize in monoclinic and triclinic space group, $\mathrm{P} 2_{1} / \mathrm{n}$ and $\mathrm{P} \overline{1}$, respectively.

The $\mathrm{Hg}$ (II) atoms of compound $\mathbf{1}$ are coordinated by three $\mathrm{Br}$ atoms and one $\mathrm{N}$ atom composing trigonal pyramidal coordination $\mathrm{Br}_{3} \mathrm{~N}$ (Fig. 1). The asymmetric unit of compound 1 contains two $\mathrm{Hg}^{2+}$ cations, which coordinate two 2-amino-4-methylpyridine ligands and four $\mathrm{Br}^{-}$anions (Fig. 4). Each 2-amino-4methylpyridine ligand in compound $\mathbf{1}$ is coordinated to one $\mathrm{Hg}$ atom by $\mathrm{N}$ atom of pyridine ring, and $\mathrm{Hg}-\mathrm{N}$ distance is about $2.23 \AA$. Additionally, three $\mathrm{Br}$ atoms are coordinated to each $\mathrm{Hg}$ (II) atom with contacts distances $\mathrm{Hg}-\mathrm{Br}$ in the range of 2.4892.974 Å (Tables 2 and 4 and Fig. 2). Two of four $\mathrm{Br}^{-}$anions are bridging between two $\mathrm{Hg}^{2+}$ cations, and two $\mathrm{Br}^{-}$are terminal occupying one vertex of base in trigonal pyramidal coordination polyhedron of each $\mathrm{Hg}^{2+}$. The coordination interactions can be separated in two groups:

(i). Strong, more valence, in short range of 2.226-2.564 Å;

(ii). Weak, more electrostatic, in long range of 2.954-2.974 Å.

Both terminal $\mathrm{Br}^{-}$ions additionally interact with neighbor $\mathrm{Hg}^{2+}$ ion, but with much longer distances $\operatorname{Hg}(1)-\operatorname{Br}(4)=3.336 \AA$ and $\operatorname{Hg}(2)-\operatorname{Br}(2)=3.321 \AA ̊$.

Strong bonds form mononuclear complexes $\left[\mathrm{Hg}(\mathrm{L})(\mathrm{Br})_{2}\right]$, which expanded by relatively weak interactions in polymeric chain $\left[\mathrm{Hg}_{2}(\mathrm{~L})_{2}(\mathrm{Br})_{4}\right]_{\mathrm{n}}$ along $a$ axis (Fig. 2). Simplification of

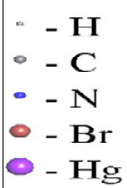

c a

b
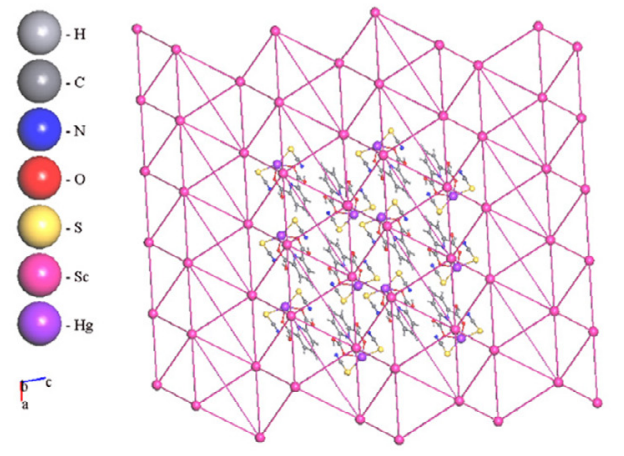
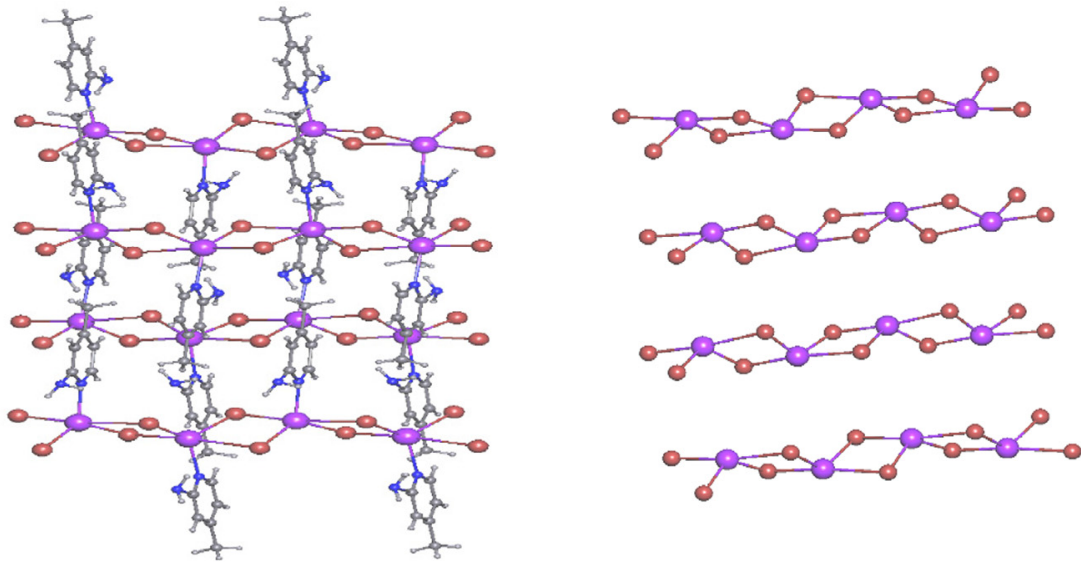

Fig. 5. Topological representation of coordination networks in compounds 1 (up) and 2 (down). 
mononuclear complexes $\left[\mathrm{Hg}(\mathrm{L})(\mathrm{Br})_{2}\right]$ into nodes of the chain underlying net and its classification by ToposPro package reveals 2C1 topological type, which is abundant for 1D coordination polymers (more than 45,000 examples in TTO collection of ToposPro (Fig. 5) [41]. Every $\left[\mathrm{Hg}_{2}(\mathrm{~L})_{2}(\mathrm{Br})_{4}\right]_{\mathrm{n}}$ chain is surrounded by six other same chains forming van-der-waals bonded hexagonal packing of cylinders (Fig.2).

In compound $\mathbf{2}$, also $\mathrm{Hg}$ (II) atoms are coordinated by five atoms and have square-pyramidal coordination sphere as $\mathrm{S}_{2} \mathrm{NO}_{2}$ (Fig. 1). Asymmetric unit cell of compound 2 consists of one $\mathrm{Hg}^{+2}$ cation, one 2,6-pyridinedicarboxlic acid ligand, and two $\mathrm{SCN}^{-}$anions (Fig. 4). Each $\mathrm{Hg}$ atom is coordinated by nitrogen (1), oxygen (2) and sulfur (2) atoms of 2,6-pyridinedicarboxlic acid ligand and $\mathrm{SCN}^{-}$anions with $\mathrm{Hg}-\mathrm{N}, \mathrm{Hg}-\mathrm{S}$ and $\mathrm{Hg}-\mathrm{O}$ distances are about 2.380-2.674 Å (Table 3 and Fig. 3). The coordination interactions can be separated in two groups: (i). Relatively strong valence in range of $2.380-2.674 \AA$;

(ii). More weak electrostatic Hg1-01 = $3.215 \AA$ Å.

In compound 2, strong bonds construct monomer complex [Hg $\left.\left(\mathrm{L}^{\prime}\right)(\mathrm{SCN})_{2}\right]$, and weak interactions assemble these complexes in supramolecular dimer $\left[\mathrm{Hg}\left(\mathrm{L}^{\prime}\right)(\mathrm{SCN})_{2}\right]_{2}$ (Fig. 3) The simplification followed by the classification of the monomer complex gives 1,3M4-1 type (63,408 entries in TTO collection of ToposPro), and for dimer topological type is 1,2,4M8-3 (10,738 entries). Every $\left[\mathrm{Hg}\left(\mathrm{L}^{\prime}\right)(\mathrm{SCN})_{2}\right]_{2}$ dimer is connected to two others by $\mathrm{H}$-bonds: $\mathrm{H}$ (4)...S(2), $\mathrm{H}(2) \ldots \mathrm{N}(2), \mathrm{H}(2 \mathrm{~A}) \ldots \mathrm{N}(3), \mathrm{H}(4 \mathrm{~A}) \ldots \mathrm{N}(2)$. The parameters of $\mathrm{H}$-bonds are listed in the (Table. 6). These interactions form chains spread along $b$ axis. The chains form sloping tetragonal packing of cylinders (Fig 3 ).

The IR spectra display characteristic absorption bands for $\mathrm{N}-\mathrm{H}, \quad \mathrm{O}-\mathrm{H}$ and the 2-amino-4-methylpyridine and 2,

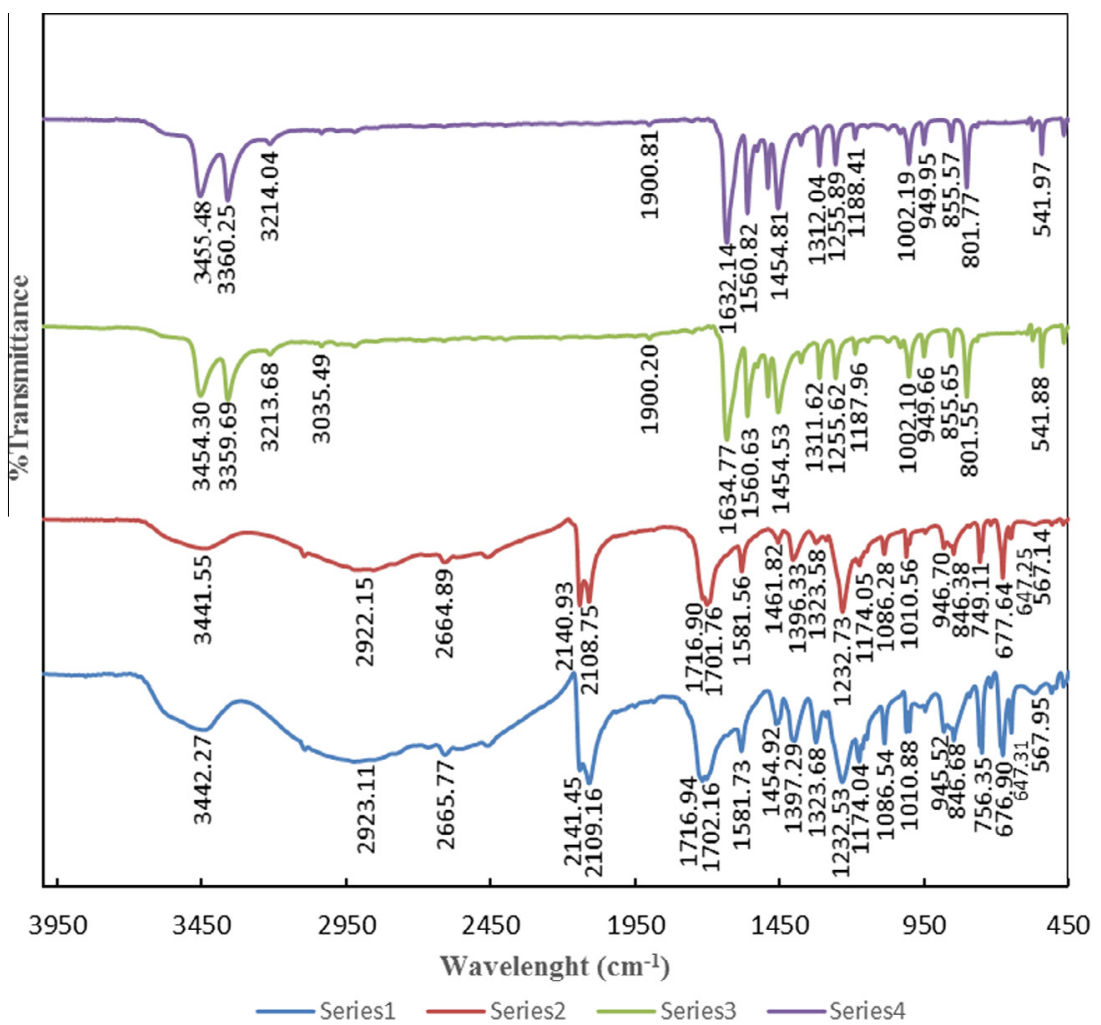

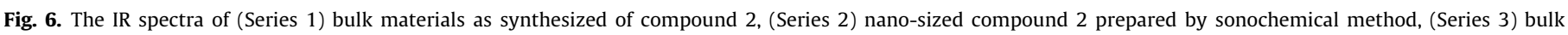
materials as synthesized of compound 1 and (Series 4 ) nano-sized compound 1 prepared by sonochemical method.

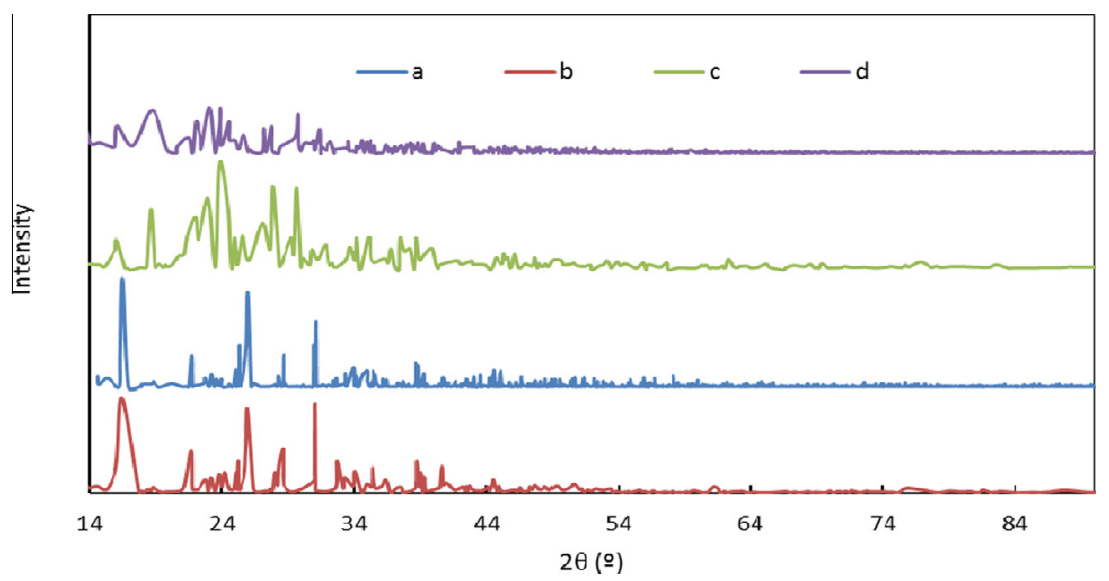

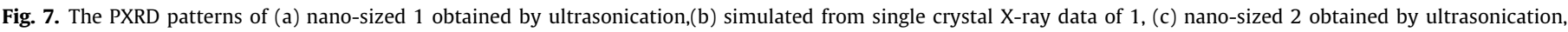
(d) simulated from single crystal X-ray data of 2 . 
6-pyridinedicarboxlic acid ligands in compounds $\mathbf{1}$ and $\mathbf{2}$. The IR spectrum of compound 2 shows the characteristic stretching frequency of $\mathrm{O}-\mathrm{H}$ group observed at about $3442 \mathrm{~cm}^{-1}$ the relatively broad absorption bands, The absorption bands with variable intensity in the frequency range $1700-1750 \mathrm{~cm}^{-1}$ correspond to $\mathrm{C}=\mathrm{O}$ stretching frequency from the carbonyl of the 2, 6pyridinedicarboxlic acid ligands. Also, characteristic band of the $\mathrm{C}-\mathrm{O}$ stretching frequency carboxylic acid group appears at $1000-1300 \mathrm{~cm}^{-1}$. The absorption bands around 2141 and $2109 \mathrm{~cm}^{-1}$ related to stretching frequency of the SCN group. For compound 1 two bands around 3454 and $3359 \mathrm{~cm}^{-1}$ are due to the $\mathrm{N}-\mathrm{H}$ stretching frequency amine group ligand. The absorption bands with variable intensity in the frequency range $1640-1560 \mathrm{~cm}^{-1}$ correspond to $\mathrm{N}-\mathrm{H}$ bending frequency of the amine group of the 2-amino-4-methylpyridine ligand, absorption bands around $1454 \mathrm{~cm}^{-1}$ related to $\mathrm{CH}_{3}$ bending. Also, aromatic $\mathrm{C}-\mathrm{H}$ stretching frequency appears at around $3035 \mathrm{~cm}^{-1}$. The elemental analysis and IR spectra of the nano-structure produced by the sonochemical method as well as the bulk material produced by the branched tube method are indistinguishable (Fig. 6).

Fig. $7 \mathrm{~b}$ and $\mathrm{d}$ shows the XRD patterns of compounds $\mathbf{1}$ and $\mathbf{2}$ simulated from single crystal X-ray data. While the experimental XRD patterns of compounds $\mathbf{1}$ and $\mathbf{2}$ prepared by the sonochemical process is shown in Fig. 7a and c, respectively. For the both compounds, acceptable matches, with slight differences in $2 \theta$, were observed between the simulated and experimental powder $\mathrm{X}$-ray diffraction patterns. This indicates that the compound 1 and 2 obtained by the sonochemical process as nano-structures are identical to that obtained by single crystal diffraction. The significant broadening of the peaks indicates that the particles are of nanometer dimensions. As Fig. 7 shows the pick is sharper and then crystal lattice will be more regular. Also, for crystal and nanostructures of compounds $\mathbf{1}$ and $\mathbf{2}$ are concluded which have same phase.

In order to look at the thermal stability of the two compounds, thermal gravimetric (TG) and differential thermal analyses (DTA) were carried out for compounds 1 and 2 between 30 and $600{ }^{\circ} \mathrm{C}$ under argon flow. The TG curve of compound $\mathbf{1}$ indicates that the compound does not melt and is stable up to $100{ }^{\circ} \mathrm{C}$ at that temperature it begins to decompose (Fig. 8). Removal of the 2-amino-4methylpyridine ligand connected to $\mathrm{Hg}$ atom takes place in the range between 190 and $330{ }^{\circ} \mathrm{C}$ with two exothermic effects at $199.87^{\circ} \mathrm{C}$ and between 250 and $300^{\circ} \mathrm{C}$ with a mass loss of $99.82 \%$, ultimately giving amorphous solid that appears to be $\mathrm{HgBr}_{2}$. The TG curve of compound 2 indicates that this compound is stable up to $190{ }^{\circ} \mathrm{C}$, at which temperature it begins to decompose (Fig. 8). Removal of the three carboxylate anions, one aromatic ring of 2,6-pyridinedicarboxlic acid ligand, and decomposition of the
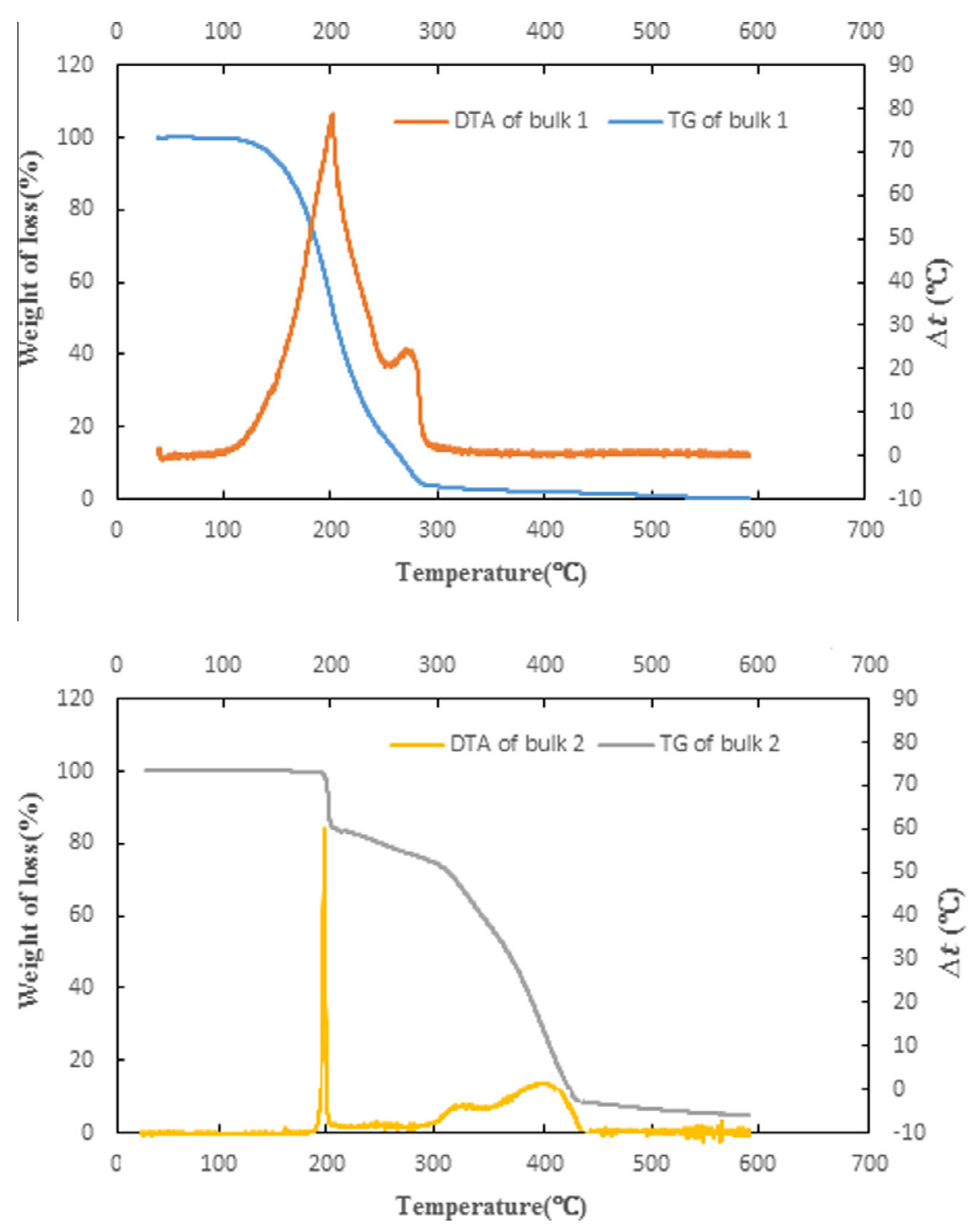

Fig. 8. Thermal behavior of compound 1 (up) and 2 (down). 
Table 5

The influence of temperature, reaction time and sonication power on the size of compound 1 and 2 particles.

\begin{tabular}{lllll}
\hline $\begin{array}{l}\text { Compound 1 } \\
\text { samples }\end{array}$ & $\begin{array}{l}\mathrm{T} \\
\left({ }^{\circ} \mathrm{C}\right)^{\mathrm{a}}\end{array}$ & $\begin{array}{l}\mathrm{T} \\
(\mathrm{min})^{\mathrm{b}}\end{array}$ & $\begin{array}{l}\text { Sonication (input power) } \\
(\mathrm{W})\end{array}$ & $\begin{array}{l}\text { Size }^{\mathrm{c}} \\
(\mathrm{nm})\end{array}$ \\
\hline $1-1$ & 50 & 60 & 0 & 617 \\
$1-2$ & 50 & 60 & 60 & 79 \\
$1-3$ & 50 & 30 & 60 & 55 \\
$1-4$ & 70 & 60 & 60 & 42 \\
Compound 2 & $\mathrm{T}$ & $\mathrm{T}$ & Sonication (input power) & $\mathrm{Size}^{\mathrm{c}}$ \\
$\quad$ samples & $\left({ }^{\circ} \mathrm{C}\right)^{\mathrm{a}}$ & $(\mathrm{min})^{\mathrm{b}}$ & $(\mathrm{W})$ & $(\mathrm{nm})$ \\
\hline $2-1$ & 50 & 60 & 0 & 590 \\
$2-2$ & 50 & 60 & 60 & 85 \\
$2-3$ & 50 & 30 & 60 & 57 \\
$2-4$ & 70 & 60 & 60 & 53 \\
\hline
\end{tabular}

a Reaction temperature.

b Reaction time.

Average diameter (nm).

thiocyanate anions takes place in three steps between 190 and $450{ }^{\circ} \mathrm{C}$ and mass loss of $95.13 \%$ with three exothermic between 190 and $550{ }^{\circ} \mathrm{C}$.

Various conditions for preparation of compounds 1 and $\mathbf{2}$ nanostructures were summarized in Table 5. In this table, sample 1-1 and 2-1 were studied without power ultrasound and the other samples were studied under variable temperature, time and power ultrasound. In order to research the role of power ultrasound irradiation on the character of product, reactions were performed under completely different power ultrasound irradiation. Results show a decrease in the particles size as increasing power ultrasound irradiation [38-40].

In sample 1-1, the reactions were studied without power ultrasound. Results show that size particles sample of 1-1
(Fig. 9a) is larger than 1-2 and $1-4$ (Fig. 9b), these results are similar with samples $2-1,2-2$ and $2-4$ (Fig. 10a, b). Table 6, shows the average diameter field emission scanning electron microscope (FESEM) and scanning electron micrographs (SEM) of the prepared samples. Results show high power ultrasound irradiation decreased agglomeration, and thus led to decrease particles size. Comparison between samples 1-2 and 1-3 shows a decrease in nanoparticle size. Thus, size particles of sample 13 are smaller than $1-2$ (Fig. 9b, c). These facts are repeated in samples 2-2 and 2-3 (Fig. 10b, c). Table 6, shows the average diameter of particles shown by field emission scanning electron microscope (FESEM) and scanning electron micrographs (SEM) of the prepared samples. However, a reducing the reaction time led to the decrease of size particles of sample 1-3. Particle sizes and morphology of nanoparticle are depending on temperature [38]. Higher temperature $\left(70^{\circ} \mathrm{C}\right)$ results in an increased solubility, and thus a reduced supersaturation of growth species in the solution, and thus particles size of sample 1-4 is smaller than particles size of sample 1-2 (Fig. 9d, b). These facts are repeated in samples 2-4 and 2-2 (Fig.10d, b). Table 5, shows the average diameter of particles shown by field emission scanning electron microscope (FE-SEM) and scanning electron micrographs (SEM) of the prepared samples. The most important point about 2, there are different morphology between Figs.10(a, b) and 10 (b, c). Pay attention to, the best conditions for getting a small sized and less agglomerated nanostructure materials for these two mercury coordination supramolecular compounds are temperature, reaction time and the power of ultrasonic irradiation $70^{\circ} \mathrm{C}, 60 \mathrm{~min}$ and $60 \mathrm{~W}$, respectively. Also, other condition (temperature $=50{ }^{\circ} \mathrm{C}$, reaction time $=30 \mathrm{~min}$ and power of ultrasonic irradiation $=60 \mathrm{~W}$ ) is good for obtaining small nanoparticle size. These two conditions led to different morphology in $\mathbf{2}$.
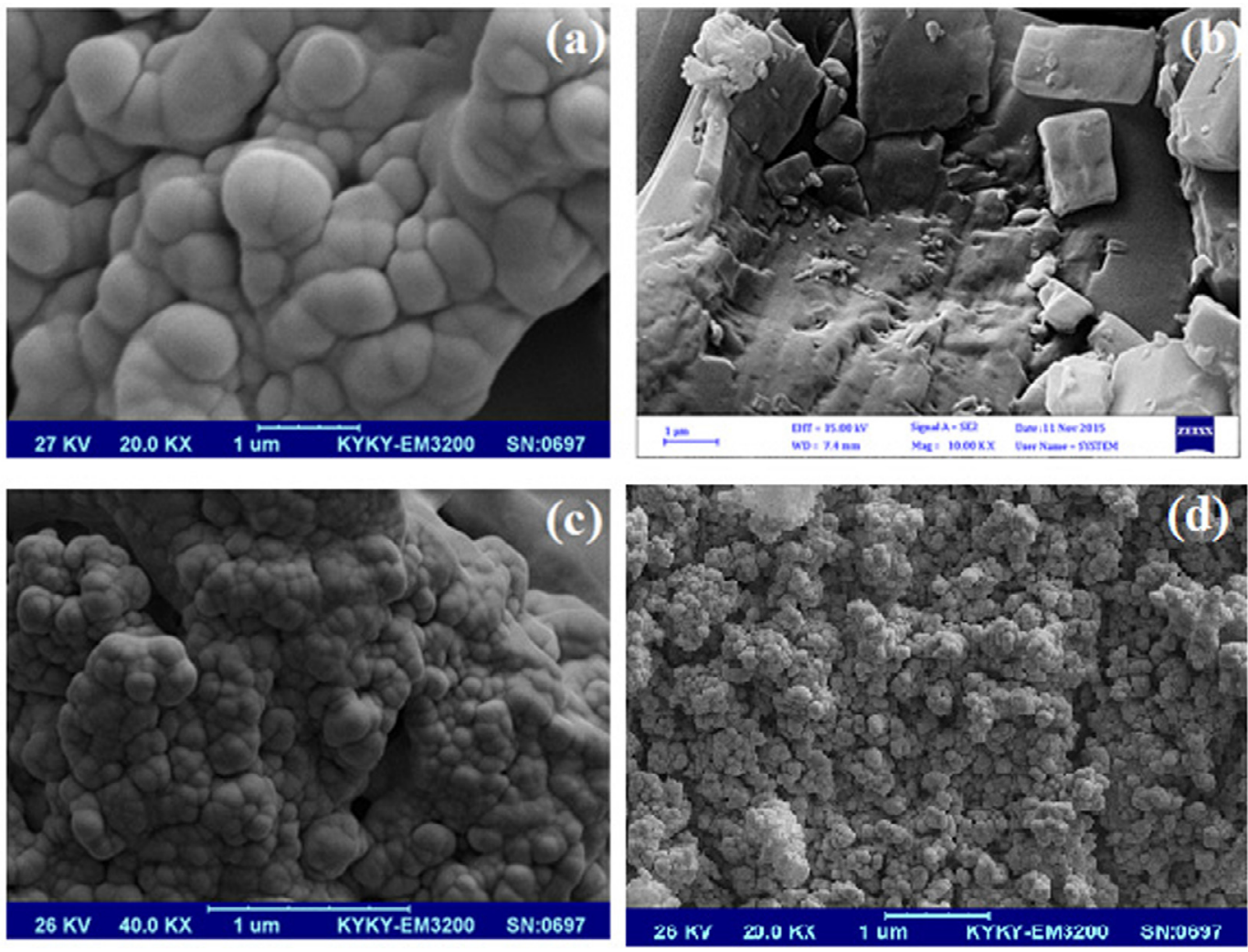

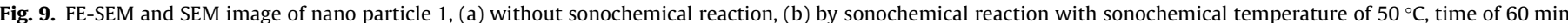

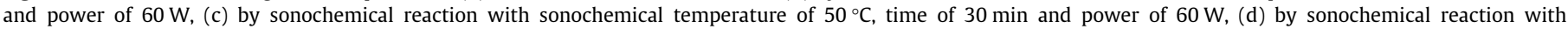
sonochemical temperature of $70^{\circ} \mathrm{C}$, time of $60 \mathrm{~min}$ and power of $60 \mathrm{~W}$. 

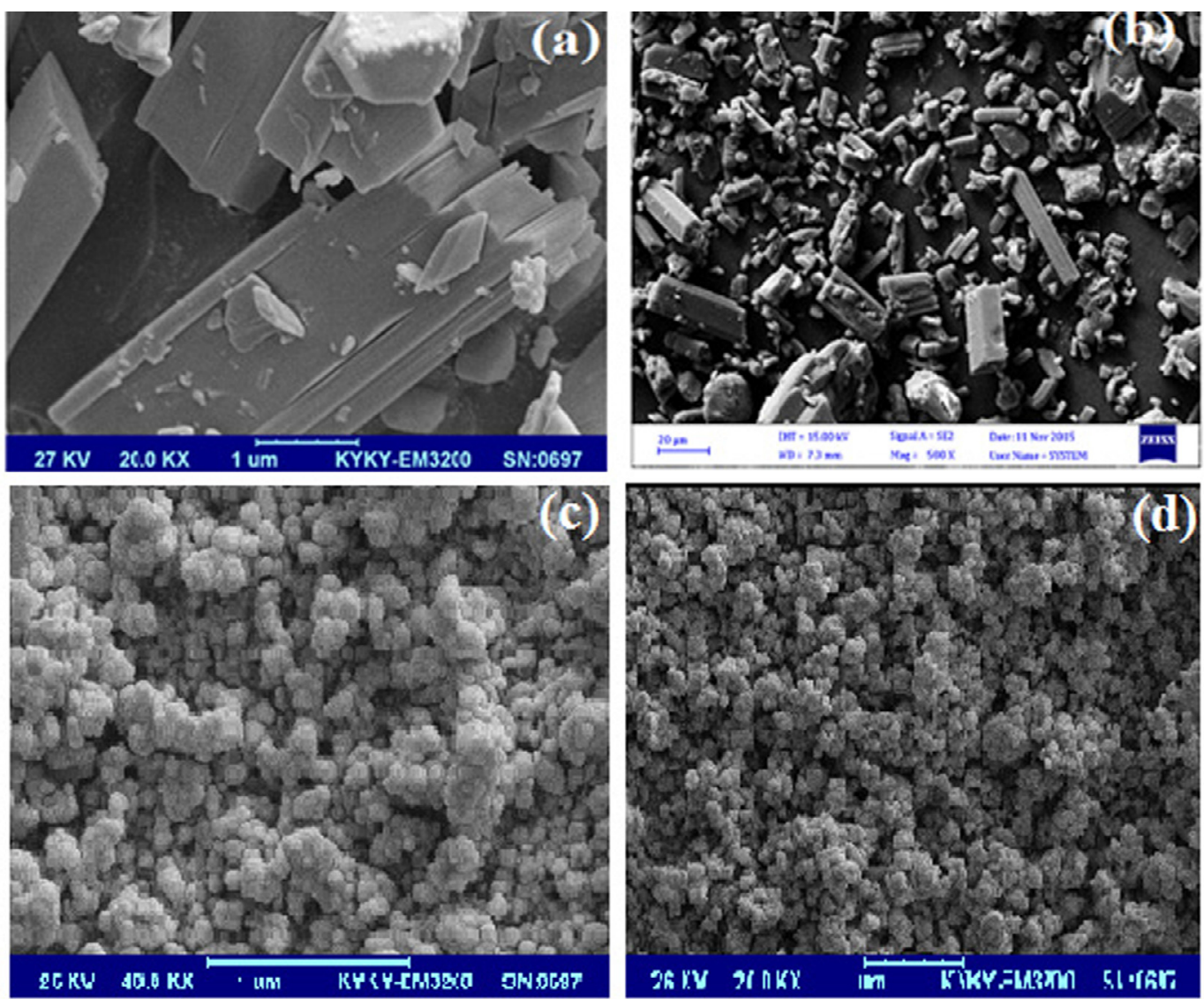

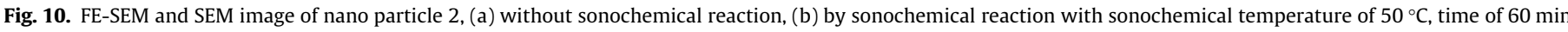

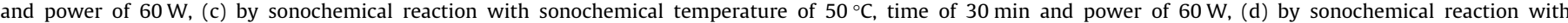
sonochemical temperature of $70{ }^{\circ} \mathrm{C}$, time of $60 \mathrm{~min}$ and power of $60 \mathrm{~W}$.

Table 6

Hydrogen bond details, distances $(\AA)$ and angles $\left(^{\circ}\right)$ for $\left[\mathrm{Hg}\left(\mathrm{L}^{\prime}\right)(\mathrm{SCN})_{2}\right]$.

\begin{tabular}{lllll}
\hline $\mathrm{D}-\mathrm{H} \ldots \mathrm{A}$ & $\mathrm{d}(\mathrm{D}-\mathrm{H})$ & $\mathrm{d}(\mathrm{H} \ldots \mathrm{A})$ & $\mathrm{d}(\mathrm{D} \ldots \mathrm{A})$ & $<(\mathrm{DHA})$ \\
\hline $\mathrm{C}(4)-\mathrm{H}(4) \ldots \mathrm{S}(2)^{\# 1}$ & 0.93 & 3.01 & $3.900(7)$ & 160.7 \\
$\mathrm{C}(2)-\mathrm{H}(2) \ldots \mathrm{N}(2)^{\# 2}$ & 0.93 & 2.54 & $3.404(9)$ & 154.0 \\
$\mathrm{O}(2)-\mathrm{H}(2 \mathrm{~A}) \ldots \mathrm{N}(3)^{\# 3}$ & $0.831(18)$ & $1.904(18)$ & $2.712(8)$ & $164(7)$ \\
$\mathrm{O}(4)-\mathrm{H}(4 \mathrm{~A}) \ldots \mathrm{N}(2)^{\# 4}$ & 0.82 & 1.94 & $2.757(8)$ & 172.7
\end{tabular}

Symmetry transformations used to generate equivalent atoms:

$\# 1 \mathrm{x}+1, \mathrm{y}, \mathrm{z}$.

$\# 2-x+1,-y+1,-z+2$.

\#3 $\mathrm{x}, \mathrm{y}-1, \mathrm{z}$.

\#4 $\mathrm{x}, \mathrm{y}+1, \mathrm{z}$.

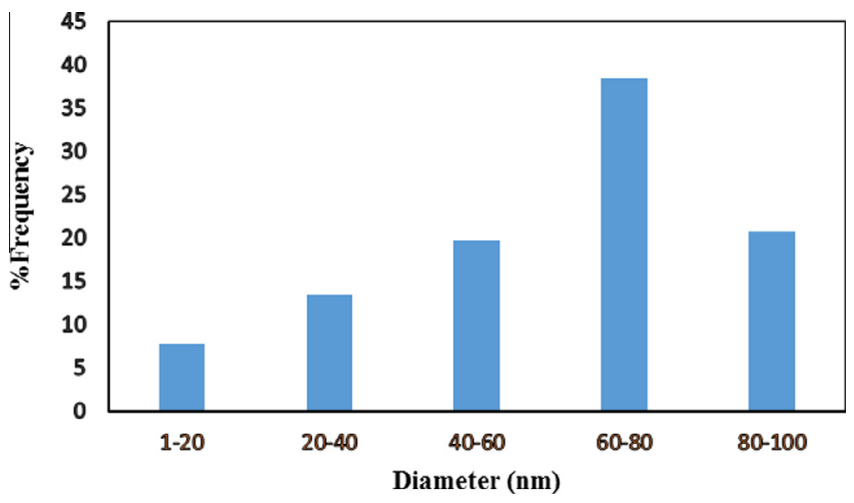

Fig. 11. Corresponding particle size distribution histogram of compound 1 nanoparticles prepared by ultrasonic generator $60 \mathrm{~W}$ in concentration of initial reagents $\left[\mathrm{Hg}^{2+}\right]=\left[\mathrm{L}^{-}\right]=\left[\mathrm{Br}^{-}\right]=0.05 \mathrm{M}$.

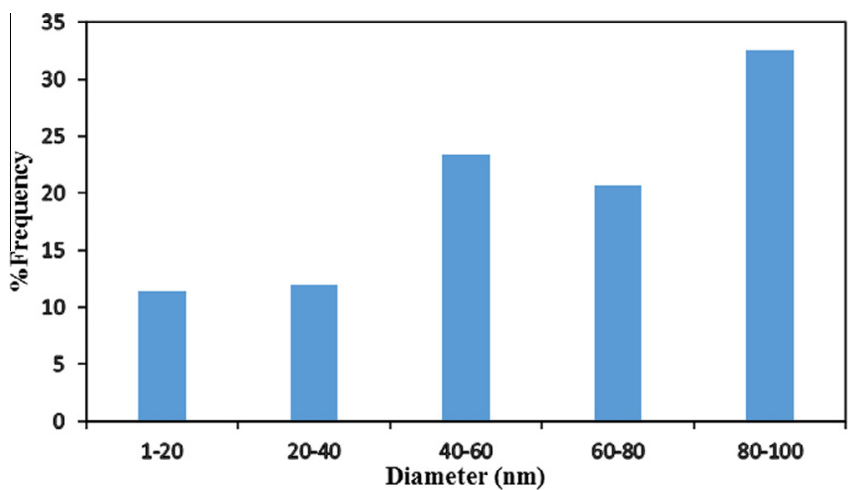

Fig. 12. Corresponding particle size distribution histogram of compound 2 nanoparticles prepared by ultrasonic generator $60 \mathrm{~W}$ in concentration of initial reagents $\left[\mathrm{Hg}^{2+}\right]=\left[\mathrm{L}^{-}\right]=\left[\mathrm{SCN}^{-}\right]=0.05 \mathrm{M}$.

Figs. 11 and 12 shows corresponding particle size distribution histogram of compound $\mathbf{1}$ and $\mathbf{2}$ nanoparticles prepared by ultrasonic generator $60 \mathrm{~W}$ in concentration of initial reagents of $0.05 \mathrm{M}$ too. In addition, is showed which maximum of frequency 1 and 2 are located range of $60-80 \mathrm{~nm}$ and $80-100 \mathrm{~nm}$, respectively.

\section{Conclusion}

Two new $\mathrm{Hg}(\mathrm{I})$ coordination supramolecular compound $\left[\mathrm{Hg}_{2}(\mathrm{~L})_{2}(\mathrm{Br})_{4}\right]_{\mathrm{n}} \quad(\mathbf{1})$ and $\quad\left[\mathrm{Hg}\left(\mathrm{L}^{\prime}\right)(\mathrm{SCN})_{2}\right] \quad$ (2), (L=2-amino-4- 
methylpyridine, $\mathrm{L}^{\prime}=2,6$-pyridinedicarboxlic acid), have been synthesized utilizing a thermal gradient approach and also by sonochemical irradiation. Compounds $\mathbf{1}$ and $\mathbf{2}$ were structurally characterized by single crystal X-ray diffraction. The crystal structures of compound $\mathbf{1}$ and $\mathbf{2}$ are made up of two 1D and OD supramolecular compounds and show the relevant coordination number for the $\mathrm{Hg}$ (II) ions is found to be four and five, respectively. Influences of temperature, power ultrasound and reaction time on the morphological properties of $\left[\mathrm{Hg}_{2}(\mathrm{~L})_{2}(\mathrm{Br})_{4}\right]_{\mathrm{n}}$ and $\left[\mathrm{Hg}\left(\mathrm{L}^{\prime}\right)(\mathrm{SCN})_{2}\right]$, were studied. These parameters have noticeable influences in the morphology of the nanoparticles. These systems depicted a decrease in the particles size accompanying an increase of the temperature, and of the power ultrasound as well as a reduction in time reaction. Also, the best conditions for getting small sized and less agglomerated nanostructure materials for these two mercury coordination supramolecular compounds are temperature, reaction time and the power of ultrasonic irradiation $70^{\circ} \mathrm{C}$, $60 \mathrm{~min}$ and $60 \mathrm{~W}$, respectively.

\section{Acknowledgement}

We are deeply indebted to Professor Lucia Carlucci (Milan, Italy) for improving early version of the paper. We would like to thanks Professor Davide. M. Proserpio (Milan, Italy) for teaching ToposPro lessons to Mr. Hayati. We gratitude to Eugeny V. Alexandrov (Samara, Russia) for many fruitful discussions about coordination compounds topology.

Support of this investigation by University of Sistan and Baluchestan (USB) and Tarbiat Modares University is gratefully acknowledged.

\section{References}

[1] B. Moulton, M.J. Zaworotko, From molecules to crystal engineering: supramolecular isomerism and polymorphism in network solids, Chem. Rev. 101 (2001) 1629-1658.

[2] S. Kitagawa, R. Kitaura, S.i. Noro, Functional porous coordination polymers, Angew. Chem. Int. Ed. 43 (2004) 2334-2375.

[3] C. Janiak, Engineering coordination polymers towards applications, Dalton Trans. (2003) 2781-2804.

[4] S.L. James, Metal-organic frameworks, Chem. Soc. Rev. 32 (2003) 276-288.

[5] L. Carlucci, G. Ciani, D.M. Proserpio, Polycatenation, polythreading and polyknotting in coordination network chemistry, Coord. Chem. Rev. 246 (2003) 247-289.

[6] K.-T. Wong, J.-M. Lehn, S.-M. Peng, G.-H. Lee, Nanoscale molecular organometallo-wires containing diruthenium cores, Chem. Commun. (2000) 2259-2260.

[7] A.G. Bunn, P.J. Carroll, B.B. Wayland, Coordination polymers of tetracyanoethylene with metal hexafluoroacetylacetonates: formation and Xray crystal structures, Inorg. Chem. 31 (1992) 1297-1299.

[8] A. Caneschi, D. Gatteschi, N. Lalioti, C. Sangregorio, R. Sessoli, G. Venturi, A. Vindigni, A. Rettori, M.G. Pini, M.A. Novak, Cobalt(II)-nitronyl nitroxide chains as molecular magnetic nanowires, Angew. Chem. Int. Ed. 40 (2001) 17601763.

[9] A. Tanatani, M.J. Mio, J.S. Moore, Chain length-dependent affinity of helical foldamers for a rodlike guest, J. Am. Chem. Soc. 123 (2001) 1792-1793.

[10] M. Fujita, Y.J. Kwon, S. Washizu, K. Ogura, Preparation, clathration ability, and catalysis of a two-dimensional square network material composed of cadmium(II) and 4, 4'-bipyridine, J. Am. Chem. Soc. 116 (1994) 1151-1152.

[11] V. Safarifard, A. Morsali, Sonochemical syntheses of a new fibrous-like nanoscale manganese(II) coordination supramolecular compound; precursor for the fabrication of octahedral-like $\mathrm{Mn}_{3} \mathrm{O}_{4}$ nano-structure, Ultrason. Sonochem. 21 (2014) 253-261.

[12] D.M.S. Paqhaleh, L. Hashemi, V. Amani, A. Morsali, A. Aminjanov, Synthesis of two new nano-structured mercury(II) complexes with 4-methyl-4H-1, 2, 4triazole-3-thiol ligand by sonochemical method, Inorg. Chim. Acta 407 (2013) $1-6$.

[13] A. Morsali, M.Y. Masoomi, Structures and properties of mercury(II) coordination polymers, Coord. Chem. Rev. 253 (2009) 1882-1905.
[14] T.S.B. Baul, S. Kundu, S. Mitra, H. Höpfl, E.R. Tiekink, A. Linden, The influence of counter ion and ligand methyl substitution on the solid-state structures and photophysical properties of mercury(II) complexes with (E)-N-(pyridin-2ylmethylidene) arylamines, Dalton Trans. 42 (2013) 1905-1920.

[15] H.R. Khavasi, A. Azhdari Tehrani, Influence of halogen bonding interaction on supramolecular assembly of coordination compounds; head-to-tail N …X synthon repetitivity, Inorg. Chem. 52 (2013) 2891-2905.

[16] H.R. Khavasi, A.A. Tahrani, The role of secondary bonding on supramolecular assembly of coordination compounds: diversity of coordination modes and supramolecular structures, CrystEngComm 15 (2013) 5799-5812.

[17] A.A. Tehrani, A. Morsali, M. Kubicki, The role of weak hydrogen and halogen bonding interactions in the assembly of a series of $\mathrm{Hg}$ (II) coordination polymers, Dalton Trans. 44 (2015) 5703-5712.

[18] H. Ghasempour, A.A. Tehrani, A. Morsali, Ultrasonic-assisted synthesis and structural characterization of two new nano-structured $\mathrm{Hg}(\mathrm{II})$ coordination polymers, Ultrason. Sonochem. 27 (2015) 503-508.

[19] J. Lorimer, T. Mason, Applied Sonochemistry: Uses of Power Ultrasound in Chemistry and Processing, Wiley-VCH, Federal Republic of Germany, 2002.

[20] K.S. Suslick, S.-B. Choe, A.A. Cichowlas, M.W. Grinstaff, Sonochemical synthesis of amorphous iron, Nature 353 (1991) 414-416.

[21] M. Sugimoto, Amorphous characteristics in spinel ferrites containing glassy oxides, J. Magn. Magn. Mater. 133 (1994) 460-462.

[22] M. Martos, J. Morales, L. Sanchez, R. Ayouchi, D. Leinen, F. Martin, J.R. Barrado, Electrochemical properties of lead oxide films obtained by spray pyrolysis as negative electrodes for lithium secondary batteries, Electrochim. Acta 46 (2001) 2939-2948.

[23] M. Landau, L. Vradman, M. Herskowitz, Y. Koltypin, A. Gedanken, Ultrasonically controlled deposition-precipitation: Co-Mo HDS catalysts deposited on wide-pore MCM material, J. Catal. 201 (2001) 22-36.

[24] H. Wang, Y.-N. Lu, J.-J. Zhu, H.-Y. Chen, Sonochemical fabrication and characterization of stibnite nanorods, Inorg. Chem. 42 (2003) 6404-6411.

[25] J. Zhang, Z. Chen, Z. Wang, N. Ming, Sonochemical method for the synthesis of antimony sulfide microcrystallites with controllable morphology, J. Mater. Res. 18 (2003) 1804-1808.

[26] M.A. Alavi, A. Morsali, Syntheses of $\mathrm{BaCO}_{3}$ nanostructures by ultrasonic method, Ultrason. Sonochem. 15 (2008) 833-838.

[27] A. Askarinejad, A. Morsali, Direct ultrasonic-assisted synthesis of sphere-like nanocrystals of spinel $\mathrm{CO}_{3} \mathrm{O}_{4}$ and $\mathrm{Mn}_{3} \mathrm{O}_{4}$, Ultrason. Sonochem. 16 (2009) $124-$ 131.

[28] M.A. Alavi, A. Morsali, Syntheses and characterization of $\mathrm{Mg}(\mathrm{OH})_{2}$ and $\mathrm{MgO}$ nanostructures by ultrasonic method, Ultrason. Sonochem. 17 (2010) 441446.

[29] M.J.S. Fard-Jahromi, A. Morsali, Sonochemical synthesis of nanoscale mixedligands lead(II) coordination polymers as precursors for preparation of $\mathrm{Pb}_{2}\left(\mathrm{SO}_{4}\right) \mathrm{O}$ and $\mathrm{PbO}$ nanoparticles; thermal, structural and X-ray powder diffraction studies, Ultrason. Sonochem. 17 (2010) 435-440.

[30] N. Soltanzadeh, A. Morsali, Syntheses and characterization of a new nanostructured bismuth(III) bromide coordination polymer; new precursor for preparation of bismuth(III) bromide and bismuth(III) oxide nanostructures, J. Coord. Chem. 62 (2009) 2869-2874.

[31] A. Askarinejad, A. Morsali, Synthesis of cadmium(II) hydroxide, cadmium(II) carbonate and cadmium(II) oxide nanoparticles; investigation of intermediate products, Chem. Eng. J. 150 (2009) 569-571.

[32] A. Morsali, H. Hosseini-Monfared, A. Morsali, P. Mayer, Sonochemical synthesis and characterization of new one-dimensional manganese(II) coordination polymer nanostructures, Ultrason. Sonochem. 24 (2015) 140-145.

[33] M.A. Alavi, A. Morsali, Syntheses and characterization of $\mathrm{Sr}(\mathrm{OH})_{2}$ and $\mathrm{SrCO}_{3}$ nanostructures by ultrasonic method, Ultrason. Sonochem. 17 (2010) 132-138.

[34] Rigaku, CrystalClear-SM expert 2.1b43, The Woodlands, Texas, USA, and Rigaku Corporation, Tokyo, Japan, 2014.

[35] G.M. Sheldrick, Acta Cryst. A71 (2015) 3-8; G.M. Sheldrick, Acta Cryst. C71 (2015) 3-8.

[36] A.L. Spek, Acta Cryst. D65 (2009) 148-155.

[37] Mercury 1.4.1, Copyright Cambridge Crystallographic Data Centre, 12 Union Road, Cambridge, CB2 1EZ, UK, 2001-2005.

[38] A.R. Abbasi, A. Morsali, Syntheses and characterization of AgI nano-structures by ultrasonic method: different morphologies under different conditions, Ultrason. Sonochem. 17 (2010) 572-578.

[39] A.R. Abbasi, A. Morsali, Formation of silver iodide nanoparticles on silk fiber by means of ultrasonic irradiation, Ultrason. Sonochem. 17 (2010) 704-710.

[40] A.R. Abbasi, A. Morsali, Influence of solvents on the morphological properties of $\mathrm{AgBr}$ nano-structures prepared using ultrasound irradiation, Ultrason. Sonochem. 19 (2012) 540-545.

[41] V.A. Blatov, A.P. Shevchenko, D.M. Proserpio, Applied topological analysis of crystal structures with the program package ToposPro, Cryst. Growth Des. 14 (2014) 3576-3586. http://topospro.com.

[42] P. Hayati, A.R. Rezvani, A. Morsali, P. Retailleau, Ultrasound irradiation effect on morphology and size of two new potassium coordination supramolecule compounds, Ultrason. Sonochem. 34 (2017) 195-205. 